\title{
Mediastinoscopy: safety and utility Cervical mediastinoscopy: assessing mediastinal lymphadenopathy at Manmohan Cardio-thoracic Vascular and Transplant center
}

\section{Bibhusal Thapa}

Manmohan Cardio-thoracic Vascular and Transplant Center.

Correspondence: Dr Bibhusal Thapa,

Email: thapabibhusal@yahoo.com

\begin{abstract}
Introduction: Mediastinoscopy is considered essential in staging of lung cancer and evaluation of mediastinal lymphadenopathy and masses. This facility has only recently been available at our center. We review our initial experience and analyse its safety and utility in our setting.

Methods: Retrospective analysis of data of all patients who underwent cervical mediastinoscopy at Manmohan Cardio-thoracic Vascular and Transplant Center (MCVTC) was done. Demographic, clinical and perioperative data were recorded. Concordance of pre and post-operative diagnosis was studied.

Results: Between January 2012 and April 2014, 24 patients underwent mediastinoscopy. The age ranged from $28-75$ years $($ mean $=43.12 \pm 15.14)$. Females outnumbered males $(\mathrm{M}$ : F = 3:5). Mediastinoscopy was done for staging of lung cancer in six patients and for assessment of mediastinal lymphadenopathy in 18 patients. One patient had a minor preoperative bleeding. One patient developed surgical site infection. The post-operative stay ranged from 1-4 days (mean $=2.15$ $\pm 0.75)$.

Concordance of pre and postoperative diagnosis was seen in 14 (58\%) patients. Amongst the five patients pre-operatively thought to have tubercular mediastinal lymphadenopathy; Tuberculosis was confirmed in only three. Only one of six patients in whom mediastinoscopy was done as a staging procedure in lung cancer was found to have malignant spread in the sampled nodes.

Conclusion: Mediastinoscopy is safe and efficacious in diagnosing mediastinal lymphadenopathy. It should be routinely considered in staging of NSCLC and evaluation of enlarged mediastinal nodes.
\end{abstract}

Keywords: Lymphadenopathy; mediastinoscopy; NSCLC.

\section{Introduction}

Histological or cytological assessment of enlarged mediastinal nodes is considered essential in the staging of non-small cell lung cancer (NSCLC) and diagnosis of mediastinal lymphadenopathy (ML) of uncertain etiology. ${ }^{1}$ $\mathrm{CT}$ assessment of the nodes based on the size, morphology, presence of necrosis and calcification has been widely used in clinical practice. However, CT assessment is not thought to be accurate in predicting the involvement of mediastinal nodes in lung cancer even when the cutoff size is taken as $20 \mathrm{~mm}^{2}$ Prediction of the etiology of isolated mediastinal lymphadenopathy based on clinical features, CT scan and biochemical tests is also often inaccurate. 
Mediastinoscopy has been the procedure of choice for the diagnostic biopsy of mediastinal nodes and a useful tool in preoperative staging of lung cancer. ${ }^{1}$ The advent of endobronchial (EBUS) and endoscopic (EUS) ultrasound with aspiration cytology more recently have made these less invasive methods more favoured over mediastinoscopy. 3,4 However, the assessment of mediastinal lymphadenopathy in our setup was based only on clinical and CT findings. Cervical mediastinoscopy has recently been introduced in our center. Here we review our experience with this procedure and analyse its safety and utility in our scenario.

\section{Methods}

A retrospective analysis of data (Thoracic Surgery database) of patients who underwent mediastinoscopy and biopsy between January 2012 and April 2014 in Thoracic Surgical unit of MCVTC was conducted. Permission was received from hospital administration to use patient information.

All patients who had undergone mediastinoscopy and biopsy for ML or for staging in patients with proven lung cancer who had significant ML on CT scan but whose lung cancer would be otherwise resectable were included in the study. The demographic data, symptoms, duration of symptoms and smoking status were recorded. The presumptive pre-operative diagnosis (based on clinical and CT scan findings), the nodes sampled, operative complications, the post-operative hospital stay, final histopathological diagnosis and further treatment required were recorded. Concordance of pre and post-operative diagnosis was analysed.

\section{Results}

Between January 2012 and April 2014, 24 patients underwent mediastinoscopy and biopsy of mediastinal nodes. Their age ranged from 28-75 years (mean $=43.12$ $\pm 15.14)$. Females outnumbered males with a M: F of 3:5. Mediastinoscopy was done for staging of lung cancer in six patients and for assessment of ML in 18 patients. Chronic cough was the commonest symptom followed by chest pain and shortness of breath. Mean duration of symptoms was $4.5 \pm 2.1$ months (2-12 months).

There were eight patients who were smokers. The proportion was higher amongst patients who were undergoing mediastinoscopy as a staging tool in lung cancer $(5 / 6)$ as opposed to those who were being assessed for ML of uncertain etiology (3/18). Based on the clinical scenario and the $\mathrm{CT}$ scan findings (size, morphology, presence/absence of necrosis, associated lung mass etc.) the pre-operative presumptive diagnosis of the ML and the final histopathological results were as shown in the table.

Save one patient who had a minor bleeding in the mediastinum controlled by use of gelfoam, there were no per-operative complications. One patient developed surgical site infection, which settled with dressing and antibiotics in one week. The post-operative stay ranged from $1-4$ days $($ mean $=2.15 \pm 0.75)$

Table. Pre-operative and post-operative diagnosis of patients who underwent mediastinoscopy.

$\begin{array}{lll}\text { Diagnosis } & \begin{array}{l}\text { Pre-operative } \\ (\mathrm{N})\end{array} & \begin{array}{l}\text { Post-operative } \\ (\mathrm{N})\end{array} \\ \begin{array}{l}\text { Ca Lung } \\ \text { metastatic nodes }\end{array} & 6 & 1 \\ \text { Lymphoma } & 3 & 1 \\ \text { Tuberculosis } & 5 & 2 \\ \text { Sarcoidosis } & 10 & 9 \\ \text { Reactive } & 0 & 5\end{array}$

Concordance of pre and post operative diagnosis was seen in $14(58 \%)$ patients. A pre-operative presumptive diagnosis of sarcoidosis was confirmed in the final histopathology in $9 / 10$ patients. Amongst the five patients pre-operatively thought to have tubercular mediastinal lymphadenopathy; Tuberculosis (TB) was confirmed in only three. One patient had sarcoidosis and in one other, it was found to harbor malignancy. Three patients who had different pre-operative diagnoses (two- lymphoma, one - sarcoidosis) were postoperatively found to have TB.

Most importantly, only one of six patients in whom mediastinoscopy was done as a staging procedure in lung cancer was found to have malignant spread in the sampled nodes. These were patients with lung cancer who were found to have significant ML on CT scan and would have been treated as $\mathrm{N} 2$ disease in the absence of mediastinal sampling. Of the five patients with lung cancer, four underwent resection of their cancers. None of these patients were found to have mediastinal nodal metastasis on the final post-resection histopathology reports. 


\section{Discussion}

The value of histological/cytological assessment in patients with lung cancer has been well established. ${ }^{5}$ This is despite the emergence of PET scan and PETCT because of the significant false positivity of these staging modalities. ${ }^{6}$ Although the preference has shifted towards less invasive procedures like EBUS and EUS, mediastinoscopy and biopsy remains the gold standard to which they are compared. ${ }^{7}$ Mediastinoscopic biopsy is also considered quintessential in the diagnosis of mediastinal lymphadenopathy and masses of uncertain origin.

Until recently our assessment of mediastinal nodes in patients with NSCLC has been based solely on CT scan findings. In our limited experience, in five out of six thought to have metastatic nodes, no metastasis was found. Four of these patients underwent surgery and final histopathology confirmed the absence of lymphatic spread. Mediastinoscopy altered the course of treatment in four of six patients with lung cancer who had enlarged mediastinal nodes. In its absence these patients would have been adjudged inoperable due to the supposition of N2 disease.

We also found significant discordance between preoperative and post-operative diagnosis in patients with mediastinal lymphadenopathy of uncertain origin. The availability of mediastinoscopic biopsy changed diagnosis in five of 18 patients. This was especially interesting in TB. Only three of five patients with a pre-operative diagnosis of tuberculosis were confirmed to harbor TB while TB was unexpectedly discovered in three others in whom the preop diagnoses were different. Misdirection of the treatment and unnecessary initiation of anti-tubercular treatment were avoided. Most importantly, a definitive diagnosis to guide subsequent therapy was attained in all cases.

Our complication rates were low and corroborated with that reported in literature. ${ }^{8,9}$ Post operative stay was longer than reported. ${ }^{9}$ This is because of our reluctance to do the procedure as a day case surgery at least in the initial phase. With experience we may be able to obviate the need for post-operative stay when the safety profile of the procedure is well established in our setting.

\section{Conclusion}

Mediastinoscopy is safe and efficacious in diagnosing mediastinal lymphadenopathy. It should be routinely considered in staging of NSCLC and evaluation of enlarged mediastinal nodes.

\section{References}

1. Scanagatta P, Bonadiman C, Falezza G, Terzi A, Magnanelli G, Benato $C$ et al. Mediastinoscopy for diagnosis of diseases of the chest and staging of lung cancer: our experience in 253 cases. ChirItal.2005 Mar-Apr;57(2):177-82. PMid:15916143

2. Kerr KM, Lamb D, Wathen CG, Walker WS, Douglas NJ. Pathological assessment of mediastinal lymph nodes in lung cancer: implications for non-invasive mediastinaltaging. Thorax.1992 May;47(5):337-41. PMid:1609375 PMCid:PMC463747. https://doi. org/10.1136/thx.47.5.337

3. Yasufuku K, Chiyo M, Koh E, et al. Endobronchial ultrasound guided transbronchial needle aspiration for staging of lung cancer. Lung Cancer.2005; 50:347. PMid:16171897. https://doi.org/10.1016/j. lungcan.2005.07.013

4. Gu P, Zhao YZ, Jiang LY, et al. Endobronchial ultrasound-guided transbronchial needle aspiration for staging of lung cancer: a systematic review and metaanalysis. Eur J Cancer. 2009; 45:1389. PMid:19124238. https://doi.org/10.1016/j.ejca.2008.11.043

5. De Leyn P, Dooms C, Kuzdzal J, Lardinois D, Passlick B, Rami-Porta R et al. Revised ESTS guidelines for preoperative mediastinal lymph node staging for non-small-cell lung cancer. Eur J Cardiothorac Surg. 2014 May;45(5):787-98. PMid:24578407. https://doi. org/10.1093/ejcts/ezu028

6. Billé A1, Pelosi E, Skanjeti A, Arena V, Errico L, Borasio $\mathrm{P}$ et al. Preoperative intrathoracic lymph node staging in patients with non-small-cell lung cancer: accuracy of integrated positron emission tomography and computed tomography. Eur J Cardiothorac Surg.2009 Sep;36(3):440-

7. PMid:19464906.https://doi.org/10.1016/j. ejcts.2009.04.003

8. Yasufuku K1, Pierre A, Darling G, de Perrot M, Waddell $\mathrm{T}$, Johnston $\mathrm{M}$ et al. A prospective controlled trial of endobronchial ultrasound-guided transbronchial needle aspiration compared with mediastinoscopy for mediastinal lymph node staging of lung cancer. J ThoracCardiovasc Surg.2011 Dec;142(6):1393400. PMid:21963329. https://doi.org/10.1016/j. jtcvs.2011.08.037

9. Application of mediastinoscopy in the differential diagnosis and preoperative staging on lung cancer. Zhongguo Fei Ai ZaZhi.2014 Feb;17(2):171-4. PMid:24581170

10. Wei B, Bryant AS, Minnich DJ, Cerfolio RJ. The Safety and Efficacy of Mediastinoscopy When Performed by General Thoracic Surgeons. Ann Thorac Surg.2014 Apr 18. pii: S0003-4975(14)00409-3. 